\title{
Increased cardiovascular mortality in people with schizophrenia: a 24-year national register study
}

\author{
J. Westman ${ }^{1 *}$, S. V. Eriksson ${ }^{2}$, M. Gissler ${ }^{1}$, J. Hällgren ${ }^{1}$, M. L. Prieto ${ }^{3,4}$, W. V. Bobo ${ }^{3}$, M. A. Frye ${ }^{3}$, \\ D. Erlinge ${ }^{5}$, L. Alfredsson ${ }^{6}$ and U. Ösby ${ }^{1,7}$ \\ ${ }^{1}$ Department of Neurobiology, Care Sciences, and Society, Division of Family Medicine, Karolinska Institutet, Stockholm, Sweden \\ 2 Department of Clinical Science, Danderyds Hospital, Stockholm, Sweden \\ ${ }^{3}$ Department of Psychiatry and Psychology, Mayo Clinic, Rochester, MN, USA \\ ${ }^{4}$ Facultad de Medicina, Departamento de Psiquiatría, Universidad de los Andes, Santiago, Chile \\ ${ }^{5}$ Department of Cardiology, Lunds Universitet, Lund, Sweden \\ ${ }^{6}$ Institute of Environmental Medicine, Karolinska Institutet, Stockholm, Sweden \\ ${ }^{7}$ Center for Molecular Medicine, Karolinska Institutet, Stockholm, Sweden
}

\begin{abstract}
Aims People who have schizophrenia die earlier from somatic diseases than do people in the general population, but information about cardiovascular deaths in people who have schizophrenia is limited. We analysed mortality in all age groups of people with schizophrenia by specific cardiovascular diseases (CVDs), focusing on five CVD diagnoses: coronary heart disease, acute myocardial infarction, cerebrovascular disease, heart failure and cardiac arrhythmias. We also compared hospital admissions for CVDs in people who had schizophrenia with hospital admissions for CVDs in the general population.
\end{abstract}

Methods This national register study of 10631817 people in Sweden included 46911 people who were admitted to the hospital for schizophrenia between 1 January 1987 and 31 December 2010. Information from national registers was used to identify people who had schizophrenia and obtain data about mortality, causes of death, medical diagnoses and hospitalisations.

Results CVDs were the leading cause of death in people who had schizophrenia (5245 deaths), and CVDs caused more excess deaths than suicide. The mean age of CVD death was 10 years lower for people who had schizophrenia (70.5 years) than the general population (80.7 years). The mortality rate ratio (MRR) for CVDs in all people who had schizophrenia was 2.80 (95\% confidence interval (CI) 2.73-2.88). In people aged 15-59 years who had schizophrenia, the MRR for CVDs was 6.16 (95\% CI 5.79-6.54). In all people who had schizophrenia, the MRR for coronary heart disease was 2.83 (95\% CI 2.73-2.94); acute myocardial infarction, 2.62 (95\% CI 2.49-2.75); cerebrovascular disease, 2.4 (95\% CI 2.252.55); heart failure, 3.25 (95\% CI 2.94-3.6); and cardiac arrhythmias, 2.06 (95\% CI 1.75-2.43). Hospital admissions for coronary heart disease were less frequent in people who had schizophrenia than in the general population (admission rate ratio, 0.88 (95\% CI 0.83-0.94). In all age groups, survival after hospital admission for CVD was lower in people who had schizophrenia than in the general population.

Conclusions People who had schizophrenia died 10 years earlier from CVDs than did people in the general population. For all five CVD diagnoses, mortality risk was higher for those with schizophrenia than those in the general population. Survival after hospitalisation for CVDs in people who had schizophrenia was comparable with that of people in the general population who were several decades older.

Received 11 August 2016; Accepted 20 March 2017; First published online 5 June 2017

Key words: Epidemiology, psychosis, suicide, schizophrenia, myocardial infarction, mortality.

\section{Background}

People with schizophrenia have a 11 to 20 years shorter lifespan than people in the general population (Laursen et al. 2013). This decreased life expectancy

* Address for correspondence: Dr J. Westman, Department of Neurobiology, Care Sciences, and Society, Division of Family Medicine, Karolinska Institutet, Alfred Nobels allé 12, SE-141 83 Huddinge, Sweden.

(Email: jeanette.westman@ki.se) may be caused by suicide or somatic illnesses, such as cardiovascular diseases (CVDs) (Brown et al. 2000; Osby et al. 2000; Nordentoft et al. 2013; Ösby et al. 2016).

People who have schizophrenia are more likely to have more than one major risk factor for CVDs; namely, overweight, smoking, high blood pressure and the metabolic syndrome (Deuschle et al. 2013; Gardner-Sood et al. 2015; Olsson et al. 2015; Gutiérrez-Rojas et al. 2016). However, they also are less likely to receive preventive care for these risk

This is an Open Access article, distributed under the terms of the Creative Commons Attribution licence (http://creativecommons.org/licenses/by/4.0/), which permits unrestricted re-use, distribution, and reproduction in any medium, provided the original work is properly cited. 
factors (Smith et al. 2013; Docherty et al. 2016). In addition, antipsychotic drugs, especially newer drugs, may cause major adverse cardiovascular events (Khasawneh \& Shankar, 2014), but the character and magnitude of their exact effect on CVD risk are controversial (Tiihonen et al. 2009; Crump et al. 2013).

Although people who have psychotic disorders have twice the risk of CVD mortality as people in the general population (Crump et al. 2013; Nordentoft et al. 2013), little information is available about the age at which premature death occurs or the effects of specific CVDs. Such information would increase our understanding of the health care needs of people who have schizophrenia - needs that often are unmet.

National Health Service registers provide the opportunity to analyse specific mortality in all patients who had schizophrenia and were admitted to the hospital in Sweden from 1987 to 2010. We used data from National Health Service registers to compare CVD mortality in adults who had schizophrenia with that of adults in the general population by age and cause of death, focusing on five categories of CVDs: coronary heart disease, acute myocardial infarction, cerebrovascular disease, heart failure and cardiac arrhythmias. Additionally, we analysed mortality from other somatic causes, suicide and accidents. We placed particular focus on early deaths (deaths before age 60). We also compared hospital admissions for CVDs in people who had schizophrenia with hospital admissions for CVDs in the general population.

\section{Methods}

\section{Cohort and follow-up}

The study cohort included the 10631817 residents of Sweden during the 24 years between 1 January 1987 and 31 December 2010, including 46911 people $(0.44 \%)$ who were diagnosed with and admitted to the hospital for schizophrenia. To evaluate morbidity and mortality for each resident of Sweden during the study period, each person's unique personal identification number was used to link data from the Swedish Total Population Register, the Swedish National Patient Register (information about hospital admissions and medical diagnoses), and the Swedish National Cause of Death Register (information about date and causes of death).

The Swedish Total Population Register, established in 1968, contains information about the sex, date of birth, place of birth and date of migration of every resident in Sweden. The Swedish National Patient Register, maintained by the National Board of Health and Welfare, contains information about all hospital inpatient treatment in Sweden, including the unique personal identification number of each patient, dates of admission and discharge and diagnoses made during each hospitalisation.

All hospital diagnoses were classified in accordance with the World Health Organization's International Classification of Diseases (ICD). Diagnostic definitions changed substantially between the earlier 8th revision of the ICD (ICD-8) and the later revisions (ICD-9 and ICD-10). We therefore included only people diagnosed with schizophrenia in accordance with ICD-9 or ICD-10 criteria. Between 1987 and 1996, ICD-9 code 295 was used to identify schizophrenia diagnoses. From 1997 onward, ICD-10 codes F20 and F25 were used to identify schizophrenia diagnoses, including schizoaffective disorder.

The Swedish National Cause of Death Register includes data about all people who were registered in Sweden at the time of their death. The register provides information from death certificates about date of death and main (underlying) and additional causes of death. In the present study, we used only the main cause of death. Deaths due to CVD (ICD-9, 401-459; ICD-10, I10-I99) were subdivided into five groups of specific interest: deaths due to coronary heart disease (ICD-9, 410-414; ICD-10, I20-I25), including acute myocardial infarction (ICD-9, 410-411; ICD-10, I20), heart failure (ICD-9, 428; ICD-10, I50) and arrhythmia (ICD-9, 427; ICD-10, I45-I49) and deaths due to cerebrovascular disease (ICD-9, 430-438, ICD-10, I60-I69). Several subgroups with small numbers of people are not included in the tables and figures; therefore, the sum of included subgroup deaths is less than the total number of coronary heart disease deaths.

People with schizophrenia $(n=46911)$ were followed up from the date of first hospital admission for schizophrenia until the earliest of three dates: date of death, date of emigration, or 31 December 2010. People in the general population $(n=10631817)$ were followed up from the date of their 15th birthday, immigration to Sweden, or 1 January 1987 (whichever came last) to the earliest of three dates: date of death, date of emigration or 31 December 2010.

\section{Statistical analysis}

Data analysis was performed with statistical software (SAS, Version 9.4, SAS Institute Inc., Cary, NC, USA). Person-years, cause-specific deaths and hospital admissions caused by CVD were calculated and stratified by sex, calendar year and 5-year age groups. Mortality rate ratios (MRRs) and admission rate ratios (ARRs) were estimated with corresponding 95\% confidence intervals (CIs) using Poisson regression models (Frome, 1983). The logarithm of the person-years of 
follow-up was used as the offset parameter. All models were adjusted for sex, age and calendar year of follow-up.

The expected number of deaths was determined by comparing the frequency of mortality in people in the general population with the frequency of mortality in people who had schizophrenia. Excess mortality in people who had schizophrenia was calculated as the difference between the observed and expected number of deaths.

When we calculated ARRs for CVD in people who had schizophrenia and people in the general population, follow-up ended on the day of first admission for CVD. For people with schizophrenia, as for people with CVD, mortality risk rises as time after diagnosis increases. We therefore used a 3-year washout period (1987-1989) to eliminate as many previous/old diagnoses of schizophrenia and CVD from our analyses as possible. That is, people who were admitted to the hospital for schizophrenia or CVD between 1987 and 1989 were excluded from the analyses.

\section{Results}

\section{MRRs and causes of death}

From 1987 to 2010, there were 13895 deaths from all causes in people in Sweden who had schizophrenia (Table 1). There were 9462 excess deaths in people who had schizophrenia (reference group: the general population). An autopsy was performed to determine the cause of death in 5422 people who had schizophrenia (39\%) and 422113 people in the general population (19\%) (data not shown).

The most common cause of death in people who had schizophrenia was CVD; there were 3372 excess deaths from CVDs in people who had schizophrenia (reference group: people in the general population) (Table 1). Coronary heart disease (including acute myocardial infarction) and cerebrovascular disease were the two most frequent cardiovascular causes of death (Table 1). Acute myocardial infarction caused more than half the deaths from coronary heart disease (Table 1). The mean age of CVD death was 70.5 years for people who had schizophrenia and 80.7 years in the general population.

In people who had schizophrenia, there were 4136 excess deaths from other somatic diseases and 1480 excess deaths from suicide.

For people between the ages of 15 and 59 years, mortality was markedly higher in people who had schizophrenia than in the general population. This was true of mortality from all causes and from CVDs, including coronary heart disease, acute myocardial infarction and cerebrovascular disease (Table 2).

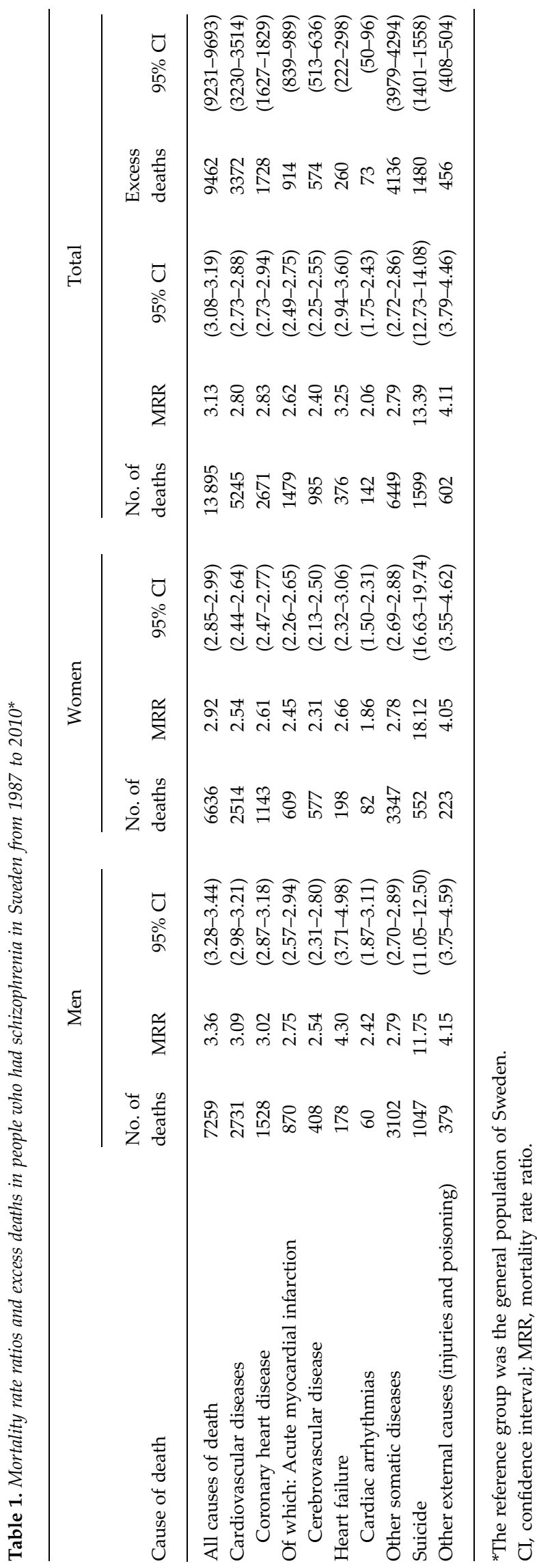


Table 2. Mortality rate ratios and excess deaths in people aged 15-59 years who had schizophrenia in Sweden from 1987 to $2010^{*}$

\begin{tabular}{lcccrrr}
\hline Cause of death & $\begin{array}{l}\text { No. of } \\
\text { deaths }\end{array}$ & MRR & 95\% CI & $\begin{array}{r}\text { Excess } \\
\text { deaths }\end{array}$ & $95 \%$ CI \\
\hline All causes of death & 4415 & 5.74 & $(5.57-5.92)$ & 3646 & $(3516-3776)$ \\
Cardiovascular diseases & 1073 & 6.16 & $(5.79-6.54)$ & 899 & $(835-963)$ \\
$\quad$ Coronary heart disease & 596 & 6.11 & $(5.64-6.63)$ & 499 & $(451-546)$ \\
Of which: Acute myocardial infarction & 341 & 5.39 & $(4.84-6.00)$ & 278 & $(242-314)$ \\
$\quad$ Cerebrovascular disease & 97 & 3.07 & $(2.52-3.76)$ & 65 & $(46-85)$ \\
$\quad$ Heart failure & 27 & 13.56 & $(9.18-20.02)$ & 25 & $(15-35)$ \\
$\quad$ Cardiac arrhythmias & 22 & 8.23 & $(5.37-12.61)$ & 19 & $(10-29)$ \\
Other somatic diseases & 1660 & 3.80 & $(3.62-3.99)$ & 1223 & $(1143-1303)$ \\
Suicide & 1405 & 15.58 & $(14.76-16.45)$ & 1315 & $(1241-1388)$ \\
Other external causes (unintentional injuries and poisoning) & 277 & 4.13 & $(3.67-4.65)$ & 210 & $(177-243)$ \\
\hline
\end{tabular}

*Men and women combined. The reference group was the general population of Sweden.

$\mathrm{CI}$, confidence interval; MRR, mortality rate ratio.

Mortality from CVDs occurred at a younger age in people who had schizophrenia than in the general population (Tables 3 and 4; Fig. 1).

\section{Hospital admissions}

In people with schizophrenia, there were more excess admissions for cerebrovascular disease than for either acute myocardial infarction or coronary heart disease (Table 5). People who had schizophrenia were not hospitalised for CVD at a frequency comparable to that of people in the general population (Table 5). Moreover, admissions to the hospital in people who had schizophrenia were not consistent with the high frequency of mortality from CVDs in this group.

In all age groups, survival after first hospital admission for CVD was lower in people who had schizophrenia than in the general population (Fig. 2). Survival was similar for people aged 20-59 years who had schizophrenia and people aged 60-79 years in the general population, and survival was similar for people aged 60 to 79 years who had schizophrenia and people aged 80 years or older in the general population (Fig. 2).

\section{Discussion}

This 24-year national register study showed that people who had schizophrenia had threefold higher mortality from CVDs than did people in the general population. For all five CVD diagnoses (coronary heart disease, acute myocardial infarction, cerebrovascular disease, heart failure and cardiac arrhythmias), mortality risk was higher for those with schizophrenia than those in the general population. CVD deaths typically occurred 10 years earlier in people who had schizophrenia. In people with schizophrenia, more excess deaths were caused by CVDs than by suicide. Frequency of hospital admission for CVDs was lower in people who had schizophrenia than in the general population.

This study used data about the entire population of Sweden aged 15 years or older. A major strength of the study was the use of register data with national coverage to evaluate the link between schizophrenia and premature cardiovascular mortality in a national cohort. The Swedish Cause of Death Register is of high quality because it covers more than 99\% all deaths in Sweden. All causes of death included in the register are diagnosed by physicians in accordance with ICD-10. Cause-of-death codes on death certificates may be imprecise for various reasons ( $\mathrm{D}^{\prime} \mathrm{Amico}$ et al. 1999; Chugh et al. 2004). However, in the present study, frequency of autopsy was twice as high in people who had schizophrenia than in the general population, which means that causes of death in people with schizophrenia were comparatively wellinvestigated.

A limitation of the present study was the exclusion of outpatient data, which was necessary to maintain uniform inclusion criteria throughout the study. The National Patient Register began to include psychiatric outpatient diagnoses in the mid-2000s. However, outpatient coverage in the register was too low during the early part of the study period to include these data in the study. Excluding outpatient data may have led us to miss people who had schizophrenia and had never been admitted to the hospital for the disorder. However, most people who have schizophrenia are 
Table 3. Relationship between age and cause of death in people who had schizophrenia in Sweden from 1987 to $2010^{*}$

\begin{tabular}{|c|c|c|c|c|c|c|c|c|c|c|c|c|c|c|c|}
\hline \multirow[b]{2}{*}{$\begin{array}{l}\text { Age } \\
\text { (years) }\end{array}$} & \multicolumn{3}{|c|}{ All causes of death } & \multicolumn{3}{|c|}{ Cardiovascular diseases } & \multicolumn{3}{|c|}{ Other somatic diseases } & \multicolumn{3}{|c|}{ Suicide } & \multicolumn{3}{|c|}{ Accidents } \\
\hline & $\begin{array}{l}\text { No. of } \\
\text { deaths }\end{array}$ & MRR & $95 \% \mathrm{CI}$ & $\begin{array}{l}\text { No. of } \\
\text { deaths }\end{array}$ & MRR & $95 \% \mathrm{CI}$ & $\begin{array}{l}\text { No. of } \\
\text { deaths }\end{array}$ & MRR & $95 \%$ CI & $\begin{array}{l}\text { No. of } \\
\text { deaths }\end{array}$ & MRR & $95 \% \mathrm{CI}$ & $\begin{array}{l}\text { No. of } \\
\text { deaths }\end{array}$ & MRR & $95 \% \mathrm{CI}$ \\
\hline 15-19 & 15 & 21.29 & $(12.83-35.34)$ & 0 & & & 1 & 4.67 & $(0.66-33.17)$ & 13 & 77.77 & $(45.00-134.38)$ & 1 & 3.38 & $(0.48-24.00)$ \\
\hline $20-24$ & 101 & 15.58 & $(12.80-18.96)$ & 1 & 3.37 & $(0.47-24.02)$ & 5 & 2.87 & $(1.19-6.91)$ & 91 & 41.61 & $(33.74-51.32)$ & 4 & 1.64 & $(0.61-4.36)$ \\
\hline $25-29$ & 201 & 12.88 & (11.19-14.81) & 8 & 7.64 & $(3.80-15.36)$ & 20 & 3.78 & $(2.44-5.87)$ & 162 & 30.52 & $(26.03-35.78)$ & 11 & 2.50 & $(1.38-4.51)$ \\
\hline 30-34 & 316 & 11.38 & $(10.18-12.74)$ & 25 & 10.19 & $(6.84-15.17)$ & 60 & 5.30 & $(4.11-6.85)$ & 198 & 22.91 & $(19.83-26.47)$ & 33 & 5.62 & $(3.98-7.93)$ \\
\hline $35-39$ & 399 & 7.92 & $(7.17-8.75)$ & 42 & 6.63 & $(4.88-9.00)$ & 101 & 4.15 & $(3.41-5.05)$ & 218 & 17.30 & $(15.08-19.85)$ & 38 & 4.86 & $(3.52-6.70)$ \\
\hline 40-44 & 551 & 6.32 & $(5.80-6.87)$ & 107 & 7.25 & (5.98-8.79) & 168 & 3.55 & (3.04-4.13) & 229 & 14.25 & $(12.47-16.29)$ & 47 & 4.61 & $(3.45-6.15)$ \\
\hline $45-49$ & 741 & 5.43 & $(5.05-5.85)$ & 176 & 6.09 & $(5.24-7.07)$ & 320 & 3.98 & $(3.56-4.44)$ & 202 & 11.91 & $(10.33-13.72)$ & 43 & 3.64 & $(2.69-4.92)$ \\
\hline $50-54$ & 908 & 4.61 & $(4.32-4.92)$ & 273 & 5.70 & $(5.05-6.42)$ & 420 & 3.42 & $(3.10-3.76)$ & 162 & 9.83 & $(8.40-11.50)$ & 53 & 4.34 & $(3.31-5.70)$ \\
\hline $55-59$ & 1183 & 4.49 & $(4.24-4.75)$ & 441 & 5.91 & $(5.37-6.49)$ & 565 & 3.37 & $(3.10-3.66)$ & 130 & 10.32 & $(8.66-12.30)$ & 47 & 4.04 & $(3.03-5.38)$ \\
\hline $60-64$ & 1307 & 3.89 & $(3.69-4.11)$ & 532 & 4.88 & $(4.48-5.32)$ & 640 & 3.04 & $(2.81-3.29)$ & 77 & 8.54 & $(6.81-10.71)$ & 58 & 5.43 & $(4.19-7.04)$ \\
\hline $65-69$ & 1489 & 3.54 & $(3.37-3.73)$ & 655 & 4.19 & $(3.88-4.52)$ & 724 & 2.88 & $(2.68-3.10)$ & 55 & 8.48 & (6.49-11.08) & 55 & 6.11 & $(4.68-7.98)$ \\
\hline 70-74 & 1722 & 3.23 & $(3.08-3.38)$ & 738 & 3.29 & $(3.06-3.53)$ & 883 & 2.97 & $(2.78-3.18)$ & 36 & 7.12 & $(5.12-9.89)$ & 65 & 6.89 & $(5.40-8.81)$ \\
\hline $75-79$ & 1799 & 2.68 & $(2.56-2.81)$ & 818 & 2.61 & $(2.43-2.79)$ & 904 & 2.64 & $(2.47-2.82)$ & 20 & 5.14 & $(3.31-7.98)$ & 57 & 4.80 & (3.70-6.23) \\
\hline$\geq 80$ & 3163 & 1.71 & $(1.66-1.78)$ & 1429 & 1.46 & $(1.39-1.54)$ & 1638 & 2.00 & $(1.91-2.10)$ & 6 & 1.43 & $(0.64-3.19)$ & 90 & 2.07 & $(1.68-2.54)$ \\
\hline
\end{tabular}

${ }^{*}$ Men and women combined. The reference group was the general population of Sweden.

$\mathrm{CI}$, confidence interval; MRR, mortality rate ratio. 
Table 4. Relationship between age and specific cardiovascular causes of death in people who had schizophrenia in Sweden from 1987 to $2010^{*}$

\begin{tabular}{|c|c|c|c|c|c|c|c|c|c|}
\hline \multirow[b]{2}{*}{ Age (years) } & \multicolumn{3}{|c|}{ Cerebrovascular disease } & \multicolumn{3}{|c|}{ Coronary heart disease } & \multicolumn{3}{|c|}{ Acute myocardial infarction } \\
\hline & No. of deaths & MRR & $95 \%$ CI & No. of deaths & MRR & $95 \% \mathrm{CI}$ & No. of deaths & MRR & $95 \% \mathrm{CI}$ \\
\hline $15-19$ & 0 & - & - & 0 & - & - & 0 & - & - \\
\hline $20-24$ & 0 & - & - & 0 & - & - & 0 & - & - \\
\hline $25-29$ & 0 & - & - & 1 & 6.11 & $(0.85-43.94)$ & 0 & - & - \\
\hline $30-34$ & 1 & 1.95 & $(0.27-13.92)$ & 10 & 14.97 & $(7.94-28.22)$ & 5 & 12.10 & $(4.95-29.55)$ \\
\hline $35-39$ & 4 & 3.01 & $(1.12-8.07)$ & 12 & 5.07 & $(2.86-8.98)$ & 3 & 1.86 & $(0.60-5.79)$ \\
\hline $40-44$ & 5 & 1.55 & $(0.64-3.74)$ & 61 & 8.78 & $(6.80-11.34)$ & 39 & 8.62 & $(6.26-11.86)$ \\
\hline $45-49$ & 23 & 3.98 & $(2.64-6.02)$ & 87 & 5.57 & $(4.50-6.89)$ & 49 & 4.81 & $(3.63-6.38)$ \\
\hline $50-54$ & 27 & 3.13 & $(2.14-4.57)$ & 159 & 5.66 & $(4.83-6.62)$ & 94 & 5.16 & $(4.21-6.33)$ \\
\hline $55-59$ & 37 & 3.03 & $(2.19-4.19)$ & 266 & 5.90 & $(5.22-6.66)$ & 151 & 5.21 & $(4.43-6.12)$ \\
\hline $60-64$ & 73 & 4.10 & $(3.26-5.17)$ & 322 & 4.79 & $(4.29-5.35)$ & 193 & 4.43 & $(3.85-5.11)$ \\
\hline $65-69$ & 114 & 4.18 & $(3.47-5.03)$ & 374 & 3.95 & $(3.56-4.37)$ & 237 & 3.81 & $(3.36-4.33)$ \\
\hline $70-74$ & 159 & 3.47 & $(2.97-4.06)$ & 385 & 3.01 & $(2.72-3.32)$ & 218 & 2.59 & $(2.27-2.96)$ \\
\hline $75-79$ & 200 & 2.75 & $(2.39-3.16)$ & 393 & 2.43 & $(2.20-2.68)$ & 206 & 1.98 & $(1.72-2.27)$ \\
\hline$\geq 80$ & 342 & 1.47 & $(1.32-1.64)$ & 601 & 1.42 & $(1.31-1.54)$ & 284 & 1.31 & $(1.17-1.47)$ \\
\hline
\end{tabular}

* Men and women combined. The reference group was the general population of Sweden.

$\mathrm{CI}$, confidence interval; MRR, mortality rate ratio.

treated at the psychiatric ward of a hospital soon after the onset of initial psychotic symptoms.

Another limitation of this study was that individuallevel data about confounding factors such as smoking, alcohol consumption, exercise and other lifestyle factors could not be included in this study because they are not available in any of the Sweden's nationwide registers. Local primary care registers may include individuallevel information about lifestyle, but it is typically incomplete. Lack of these data meant that we could not analyse the degree to which lifestyle factors explain the differences in CVD mortality between people with schizophrenia and people in the general population.

Previous studies have evaluated CVD-related deaths in people who had schizophrenia (Saha et al. 2007; Fan et al. 2013). A meta-analysis of 13 cohort studies showed that schizophrenia is significantly associated with an increased risk of mortality from CVDs (Fan et al. 2013). The present study adds new information about the age at which CVD death occurs in people who have schizophrenia and provides more detailed information about the magnitude of the problem. The present study showed that for people between the ages of 15 and 59 years, acute myocardial infarction was fivefold more frequent in those who had schizophrenia than in the general population. Furthermore, people who had schizophrenia were not hospitalised for their CVD at the same frequency as people in the general population. After hospital admission for CVD, those who had schizophrenia died more frequently than those in the general population, which suggests that CVD was inadequately treated in people who had schizophrenia.

As expected, we observed that people who had schizophrenia had increased suicide mortality. Although suicide frequency was 13-fold higher in people who had schizophrenia than in the general population, suicide caused fewer excess deaths (1480 excess deaths) than CVD (3372 excess deaths).

Although the data available in Swedish national registers did not enable us to adjust for lifestyle-related risk factors for CVD, other studies have shown that people who have schizophrenia are more likely to have at least one such risk factor, such as diabetes, smoking or hypertension (Gardner-Sood et al. 2015; Olsson et al. 2015). People who have schizophrenia are also less likely to receive good preventive somatic care than people without schizophrenia (Smith et al. 2013). In addition, antipsychotic drugs have been associated with adverse cardiovascular events (Mackin et al. 2008; Khasawneh \& Shankar, 2014). Secondgeneration antipsychotic drugs may increase mortality via metabolic pathways that involve weight gain, diabetes and dyslipidaemia (Newcomer \& Haupt, 2006; Ray et al. 2009). These are known problems and therefore important to take into account in monitoring and treatment (Buckley et al. 2005; Barnes et al. 2007; Morrato et al. 2008; Mitchell et al. 2012). However, some studies have shown no association between clozapine or other commonly used antipsychotic drugs 

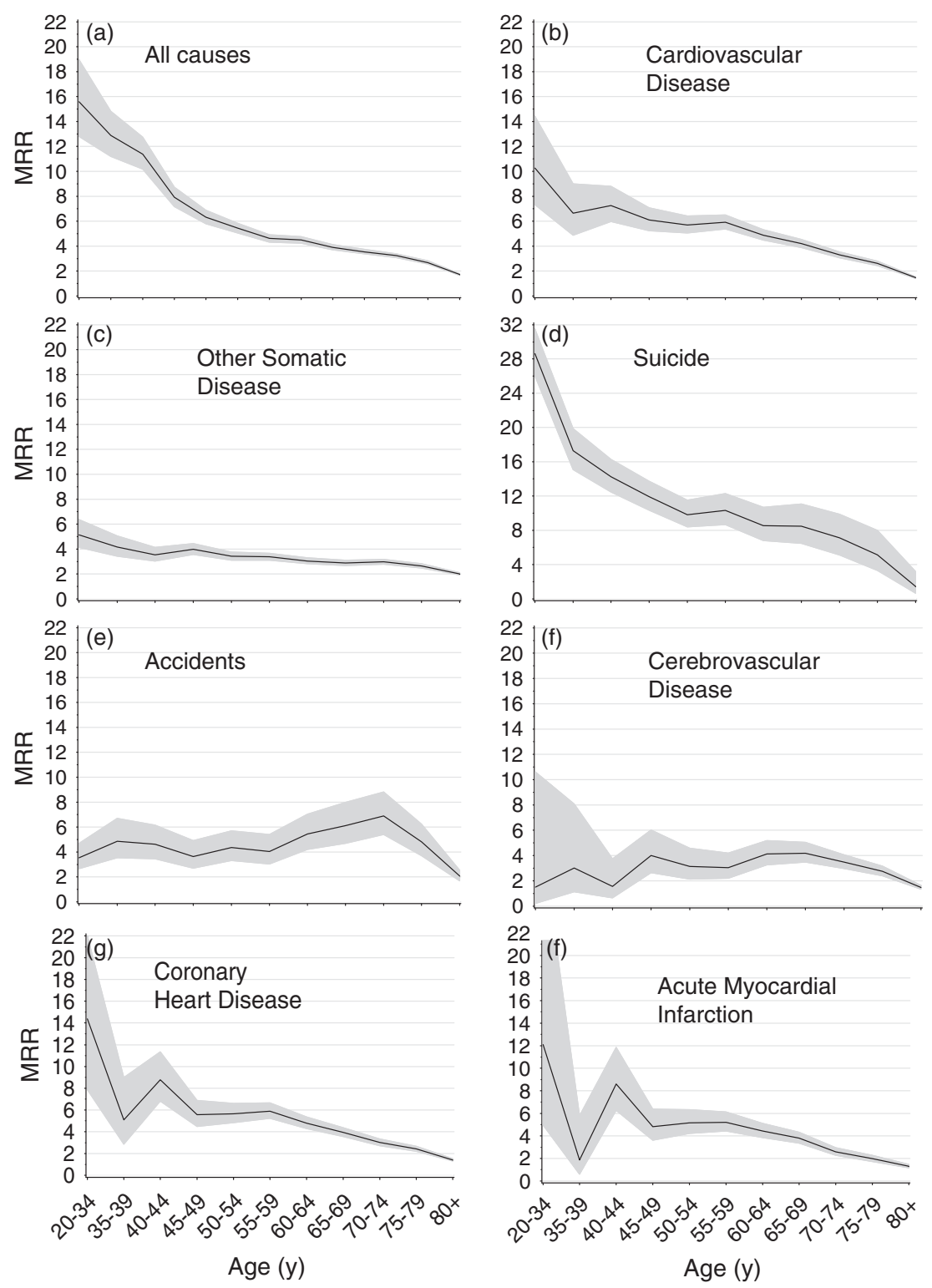

Fig. 1. Mortality rate ratio (MRR) and age by cause of death in people who had schizophrenia in Sweden between 1990 and 2010. The reference group is the general population of Sweden. The black line represents the MRR, and the grey shading represents the $95 \%$ CI.

and increased mortality (Crump et al. 2013) or a negative association (Tiihonen et al. 2009).

In summary, this large national Swedish register study showed that those with schizophrenia had higher mortality from CVDs than those in the general population. Additionally, the study provides new and more detailed information about this mortality. First, mortality risk from five CVD diagnoses was higher in people with schizophrenia than in people in the general population. Second, the risk of dying from CVDs was six times higher in younger people (under 60 years) with schizophrenia; deaths from CVDs occurred
10 years earlier in people with schizophrenia than in people in the general population. Third, CVDs were the main reason for premature death in people who had schizophrenia, accounting for more excess deaths than suicide. Fourth, in people with schizophrenia, survival after hospitalisation for CVDs was similar to that of people in the general population who were decades older. The large number of excess deaths, low hospital admission frequency and poor survival after first hospital admission indicate that CVDs were undertreated in people who had schizophrenia, especially younger people. 


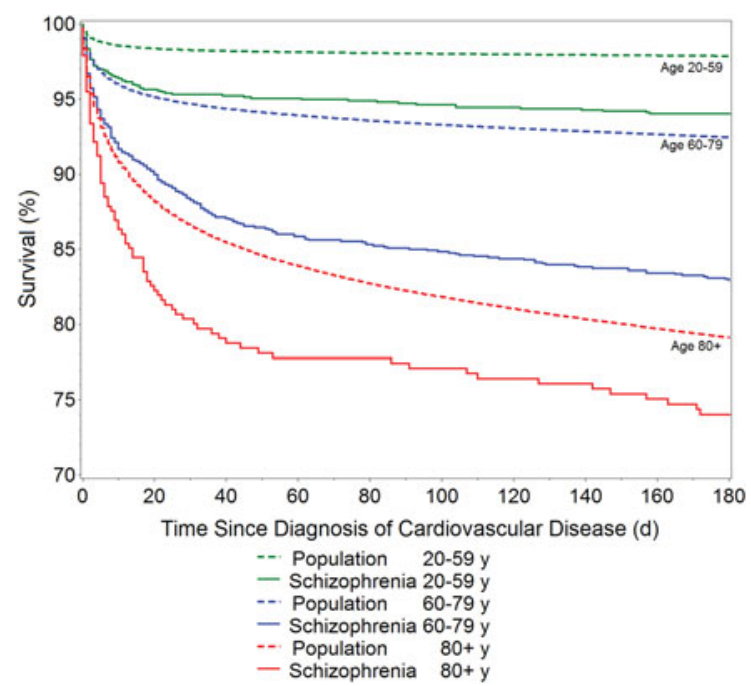

Fig. 2. Survival after first hospital admission for cardiovascular disease in people who had schizophrenia and people in the general population in Sweden.

\section{Acknowledgements}

We thank scientific editor Kimberly Kane for useful comments on the text.

\section{Financial support}

This work was supported by grants provided by the Stockholm County Council (grant no. 20140328) and the Swedish Research Council for Health, Working Life and Welfare (Forte) (grant no. 20080885).

\section{Conflicts of interest}

None.

\section{Ethical standards}

The study was approved by the Regional Ethical Committee in Gothenburg (Dnr 130-08). J.W., J.H. and U.Ö. had full access to all the data in the study and take full responsibility for the integrity of the data and the accuracy of the analyses.

\section{Availability of data and materials}

All register information was provided by the Swedish National Board of Health and Welfare. Information about how to apply for data from Swedish health care registers is available at www.socialstyrelsen.se. 


\section{References}

Barnes TR, Paton C, Cavanagh MR, Hancock E, Taylor DM (2007). A UK audit of screening for the metabolic side effects of antipsychotics in community patients. Schizophrenia Bulletin 33, 1397-1403.

Brown S, Barraclough B, Inskip H (2000). Causes of the excess mortality of schizophrenia. British Journal of Psychiatry 177, 212-217.

Buckley PF, Miller DD, Singer B, Arena J, Stirewalt EM (2005). Clinicians' recognition of the metabolic adverse effects of antipsychotic medications. Schizophrenia Research 79, 281-288.

Chugh SS, Jui J, Gunson K, Stecker EC, John BT, Thompson B, Ilias N, Vickers C, Dogra V, Daya M, Kron J, Zheng ZJ, Mensah G, McAnulty J (2004). Current burden of sudden cardiac death: multiple source surveillance versus retrospective death certificate-based review in a large U.S. community. Journal of the American College of Cardiology 44, 1268-1275.

Crump C, Winkleby MA, Sundquist K, Sundquist J (2013). Comorbidities and mortality in persons with schizophrenia: a Swedish national cohort study. American Journal of Psychiatry 170, 324-333.

D'Amico M, Agozzino E, Biagino A, Simonetti A, Marinelli P (1999). Ill-defined and multiple causes on death certificates - a study of misclassification in mortality statistics. European Journal of Epidemiology 15, 141-148.

Deuschle M, Paul F, Brosz M, Bergemann N, Franz M, Kammerer-Ciernioch J, Lautenschlager $\mathbf{M}$, Lederbogen $\mathbf{F}$, Roesch-Ely D, Weisbrod M, Kahl KG, Reichmann J, Gross J, Umbreit J (2013). Assessment of cardiovascular disease risk in patients with schizophrenia spectrum disorders in German psychiatric hospitals: results of the pharmacoepidemiologic CATS study. Social Psychiatry and Psychiatric Epidemiology 48, 1283-1288.

Docherty M, Stubbs B, Gaughran F (2016). Strategies to deal with comorbid physical illness in psychosis. Epidemiology and Psychiatric Sciences 25, 197-204.

Fan Z, Wu Y, Shen J, Ji T, Zhan R (2013). Schizophrenia and the risk of cardiovascular diseases: a meta-analysis of thirteen cohort studies. Journal of Psychiatric Research 47, 1549-1556.

Frome EL (1983). The analysis of rates using Poisson regression models. Biometrics 39, 665-674.

Gardner-Sood P, Lally J, Smith S, Atakan Z, Ismail K, Greenwood KE, Keen A, O'Brien C, Onagbesan O, Fung C, Papanastasiou E, Eberhard J, Patel A, Ohlsen R, Stahl D, David A, Hopkins D, Murray RM, Gaughran F, IMPaCT team (2015). Cardiovascular risk factors and metabolic syndrome in people with established psychotic illnesses: baseline data from the IMPaCT randomized controlled trial. Psychological Medicine 45, 2619-2629.

Gutiérrez-Rojas L, Pulido S, Azanza JR, Bernardo M, Rojo L, Mesa FJ, Martínez-Ortega JM (2016). Risk factor assessment and counselling for 12 months reduces metabolic and cardiovascular risk in overweight or obese patients with schizophrenia spectrum disorders: the CRESSOB study. Actas Españolas de Psiquiatría 44, 20-29.
Khasawneh FT, Shankar GS (2014). Minimizing

cardiovascular adverse effects of atypical antipsychotic drugs in patients with schizophrenia. Cardiology Research and Practice 2014, 273060.

Laursen TM, Wahlbeck K, Hällgren J, Westman J, Ösby U, Alinaghizadeh H, Gissler M, Nordentoft M (2013). Life Expectancy and Death by Diseases of the Circulatory System in Patients with Bipolar Disorder or Schizophrenia in the Nordic Countries. PLoS One 8, e67133.

Mackin P, Bishop D, Watkinson HM, Ferrier IN (2008). A prospective study of glycaemic status in anti-psychotictreated patients. Journal of Psychopharmacology 22, 563-566.

Mitchell AJ, Delaffon V, Vancampfort D, Correll CU, De Hert M (2012). Guideline concordant monitoring of metabolic risk in people treated with antipsychotic medication: systematic review and meta-analysis of screening practices. Psychological Medicine, 125-147.

Morrato EH, Newcomer JW, Allen RR, Valuck RJ (2008). Prevalence of baseline serum glucose and lipid testing in users of second-generation antipsychotic drugs: a retrospective, population-based study of Medicaid claims data. Journal of Clinical Psychiatry 69, 316-322.

Newcomer JW, Haupt DW (2006). The metabolic effects of antipsychotic medications. Canadian Journal of Psychiatry 51, 480-491.

Nordentoft M, Wahlbeck K, Hällgren J, Westman J, Osby U, Alinaghizadeh H, Gissler M, Laursen TM (2013). Excess mortality, causes of death and life expectancy in 270,770 patients with recent onset of mental disorders in Denmark, Finland and Sweden. PLoS ONE 8, e55176.

Olsson E, Westman J, Sudic Hukic D, Eriksson SV, Edman G, Bodén R, Jedenius E, Reutfors J, Berntsson A, Hilding A, Schalling M, Östenson CG, Ösby U (2015). Diabetes and glucose disturbances in patients with psychosis in Sweden. BMJ Open Diabetes Research and Care 3, e000120.

Osby U, Correia N, Brandt L, Ekbom A, Sparén P (2000). Mortality and causes of death in schizophrenia in Stockholm county, Sweden. Schizophrenia Research 45, 21-28.

Ösby U, Westman J, Hällgren J, Gissler M (2016). Mortality trends in cardiovascular causes in schizophrenia, bipolar and unipolar mood disorder in Sweden 1987-2010. European Journal of Public Health 26, 867-871.

Ray WA, Chung CP, Murray KT, Hall K, Stein CM (2009). Atypical antipsychotic drugs and the risk of sudden cardiac death. New England Journal of Medicine 360, 225-235.

Saha S, Chant D, McGrath J (2007). A systematic review of mortality in schizophrenia: is the differential mortality gap worsening over time? Archives of General Psychiatry 64, 1123-1131.

Smith DJ, Langan J, McLean G, Guthrie B, Mercer SW (2013). Schizophrenia is associated with excess multiple physical-health comorbidities but low levels of recorded cardiovascular disease in primary care: cross-sectional study. BMJ Open 3, pii: e002808. doi: 10.1136/bmjopen2013-002808.

Tiihonen J, Lönnqvist J, Wahlbeck K, Klaukka T, Niskanen L, Tanskanen A, Haukka J (2009). 11-year follow-up of mortality in patients with schizophrenia: a populationbased cohort study (FIN11 study). Lancet 374, 620-627. 